\title{
CULTURAL CONTEXT AND CROSS-CULTURAL MARKETING STRATEGIES BETWEEN ITALY AND CHINA. THE CASE OF AMARENA FABBRI
}

\author{
Tiziano Vescovi \\ Federica Bettati \\ Ca’ Foscari University of Venice \\ Italy
}

\begin{abstract}
Purpose. Globalization of markets creates a perception of homogeneity that should be verify. In Introducing a new product in a culturally distant market international companies should analyze the cultural context and verify the consistency between their marketing offer and the destination market. This paper aims to analyze if and how the cultural context affects the international marketing strategy of a company.

Design approach. In order to analyze the influence of the cultural context on international marketing strategies, a qualitative research has been developed using focus group technique. Three different focus groups, have been developed, targeting Generation Z, Young Mathers and Young Professionals

Finding. The research highlighted that the Chinese consumers have a different perception, use, and role of the product, compared to the ones in the traditional international markets of the company, pushing the company to reconsider its international strategy in different cultural contexts.

Research limitation. The research process was limited because based only on one case study, even if emblematic, and only on three targets in an internationalized context as the city of Shanghai.

Practical implications. Managers should develop international marketing strategy after a deep analysis of the cultural context of the destination market and adapt it to the local perception and the cultural assessment of the product.

Originality. The use of focus group methodology in order to indagate how the cultural context can influence the perception of the product is not used in marketing research literature, despite its evident effectiveness in such a purpose.
\end{abstract}

Keywords: Cross-cultural marketing; International marketing strategy; Chinese consumers 


\section{Introduction: a cross-cultural approach}

Modernization theories of the 1960s raised the idea of an emergence of a unique world culture following the maturity of developed counties markets (Hofstede 1991). Consumer behavior theorists were supposing that consumers in all parts of the world were adopting Western consumption values (Robertson 1992).

Ted Levitt (1983) argued that new technology would lead to homogenization of consumer wants and needs, because consumers would prefer standard products of high-quality at a low price to more customized high-priced products. This argument is, specifically, based on the classical microeconomic theory which imagines the consumer as rational and essentially taking two type of decisions: the type of product to purchase and the quantity to purchase, and the solution would be enough to maximize utility and satisfaction of needs. The concept of the rational universal consumer is increasingly regarded as unrealistic and places consumers outside a cultural context (Suerdem 1994).

Modern societies are characterized by rapid communication and transportation, urbanization, industrialization and bureaucratization; the term "modern" refers to anything that has, more or less, replaced something that was considered the traditional ways of doing things. Although modernization is an important force of change and development, it does not directly imply a convergence of value or the emergence of a global culture. For example, Asians view modernization as involving technology, behavior, or material progress, without cultural implications (Fu and Chiu 2007). As Mooney (2002) stated in his article: "The expectations were that with increased openness and capitalism in China, the Chinese would turn to Western values. Instead, they are rediscovering the teachings of Confucius, which for centuries have been the moral guidance of Chinese people. China want to become modern while retaining its core values".

About the influence of education on consumer behavior, better-educated consumers are assumed to be better informed, but the information process is another aspect affected by culture; in fact, the way consumers around the globe search for information is different in relation to individualism/collectivism and high/low power distance cultures (de Mooij 2011). According to the social phenomena just analyzed, it is possible to assume that convergence follows economic development, but at macro level, which means only dealing with aspects 
of consumption, health, social welfare, possession of communication means, education levels of countries, infrastructure, etc. Economic development, in this sense, allows global brands' entrance in developing countries; but the spread of global symbols does not imply the existence of a global consumer culture, at the opposite, what people possess does not converge with the usage of the same goods, as each consumer has his or her personal way of utilizing his belongings. It can be assumed that globalization is the reason for revival of local cultural identities in different parts of the world, instead of causing homogenization (Giddens 2000).

The emergence of middle-income society in developing countries can be an explanation of this economic phenomenon, as it tends to manifest cultural values of that country reflected in the different choices of products and brands.

\section{Dimensions of culture}

According to Hofstede (2003), culture is "the collective programming of the mind that distinguishes the members of one group or category of people from another". He defines the value construct as "a broad tendency to prefer certain states of affairs over others". Cultural values can be most powerful explanations of, and influences on consumer behavior (Terlutter et al., 2006). For cross-cultural research in international marketing a much-used method is secondary analysis of consumer behavior data using country scores of dimensional models of national culture. These models or frameworks are constructs that include cultural values that were measured at the national level. Several dimensional models of national culture are available that can be used for cross-cultural research in international marketing to find explanations for consumer behavior differences by Edward Hall (1976), Geert Hofstede (2003), Shalom Schwartz (1992, 1994, 2006) and project GLOBE (House et al., 2004). Culture can be used as an explanatory variable depending upon the ability to "unpackage" the culture concept (Rohner, 1984); it is therefore best to view culture as a complex multidimensional structure rather than as a simple categorical variable. Culture can be described according to specific characteristics, based on observations, and many of these are found in dimensional models derived from large surveys (de Mooij 2011).

McCracken (1986) posed that the world of everyday experiences was shaped and constituted by the beliefs and assumptions of an individual's culture. Culture has been referred by Engel 
et al. (1993) as "a set of values, ideas, artefacts, and other meaningful symbols that help individuals communicate, interpret, and evaluate as members of society". They recognize that culture not only affects the specific products people buy but also the structure of consumption, individual decision-making and communication about the product.

According to the psychologist Oyserman (2015), if made salient both individual values and cultural values are linked with and can predict behavior and choices. Both values and related actions may vary across cultures. Thus, two societies can both value achievement but differ tremendously in their norms as to what to achieve, how to achieve and when pursuing achievement is appropriate. Trompenaars (1993), for instance, applied the five orientations to countries and presented categories of work-related values but, these categories being not statistically independent, could not produce country scores.

The anthropologist Edward Hall (1976,1984,1988) distinguished patterns of culture according to context, space, time, and information flow. For the study of consumer behavior, fundamentals among Hall's studies (1988) are: the human relationship with nature, the context orientation and the time concept. The view of Western culture is that it is the person's responsibility to overcome obstacles that may stand in his or her way. The East Asian experience of nature is one of communion, of exchange, characterize by a subtle intimacy. In Chinese, particularly, the word used to name nature is daziran which literally means "great spontaneity, infinity of spontaneity", expressing something that human beings are not capable to control or dominate. The context orientation developed by Hall divides cultures in highcontext and low-context communication cultures. In high-context communication or message, most of the information is either part of the context or internalized in the person; very little is made explicit as part of the message. At the opposite, the information of a lowcontext message is direct and unambiguous; Low-context communication cultures demonstrate positive attitudes toward words. Another characteristic of high-context culture is homogeneity; thus, their members have more in common with respect to cultural heritage. The context orientation can be related to Hofstede's individualism-collectivism dimension. Although the model by Geert Hofstede $(2003,2010)$ was developed to explain differences in work-related values, over time it has been increasingly used for comparative cross-cultural studies and provides useful explanations of cross-cultural differences in consumer behavior. 
According to the Chinese point of view, the reason they require time is for attaining a degree of closeness high enough to build common trust and intent to better deal future relationships. The time concept is of fundamental importance and has to be carefully considered by all the foreign companies aiming to enter the Chinese market, with new or existing products.

Despite Hall did not develop country scores, his findings show a certain robustness for crosscultural studies: the context concept is useful for understanding consumer behavior across cultures. An individual's behavior is a result of that individual's cultural value system for a particular context (Luna and Gupta 2001).

Other models have been developed by de Mooij, by Shalom Schwartz, and the more recent GLOBE study. The study of de Mooij (2016) was meant to define differences and similarities of those three major cross-cultural dimensional models for explaining consumer behavior differences, to assist academic researchers.

The model by Schwartz is less used in quantitative cross-cultural studies than Hofstede's one, but it is attractive to the marketing research because through value types it describes imaginary consumers in terms of abstract preferences like pleasure, sensuous gratification, excitement, novelty, challenge, or hedonism. The GLOBE study (House 2004) measures the desired and the desirable of respondents probing them about organization and societies in which they live or work as it is and as it should be. Cultural dimensions are human constructs. Although they are based on objectively existing phenomena, they are not the phenomena themselves but ways of describing them. The same reality can be explained and presented in different ways, through different constructs (Minkov 2007). The three models just presented overlap in some ways, but they vary with the respect to sampling and type of questions used. They are different with respect to the level of analysis - individual versus cultural level - and the dimension structure. However, they all gave predominant emphasis upon characterizing cultures in terms of shared values, shared beliefs, or shared sources of guidance (Smith 2006). Cultural models are increasingly applied in international business, marketing, and advertising research. These models may lose credibility by improper application as often such studies are not based on sufficient conceptual insight into the various cultural dimensions. New models are quickly embraced without proper analysis of the conceptual content. Loss of credibility of cultural models is also caused by using the same labels for different concepts. 
Hofstede's model is considered to be more useful in predicting behavior, the Schwartz model is useful to study both individual-level values and culture-level values, and the GLOBE value dimensions could prove more usefulness in predicting the impact of cultural variables on leadership and organizational processes. Hofstede's framework constitutes a simple, practical, and usable shortcut to the integration of culture into studies. In spite of some criticisms to his dimensions, the argument that they capture cross-country differences has received extensive support (Soares et al. 2007).

\section{Culture, product perception and purchase intention}

Empirical studies of consumer behavior have also acknowledged the role that culture plays in the consumers' decision-making process: it affects the drives that motivate people to take further action, determines what forms of communication are permitted about problems at hand (Delener and Neelankavil, 1990; O'Guinn and Meyer, 1984) and even the degree of search behavior that an individual deems appropriate (Hirschman, 1981). International marketers would be, nay should be, extremely interested in consumers' willingness to accept or reject new products and ideas and the factors which determine this behavior (Singh 2006). The concept under study in these cases has been termed "national character" or "national culture" (Clark, 1990; Hofstede, 2010; Nakata and Sivakumar, 1996) and has been considered useful in its potential to explain aggregate national consumer behaviour.

Despite radical changes are taking place in the molding consumer behavior, the cultural factors dramatically impact the patterning of markets, the formation of consumer tastes and preferences, their information seeking and purchase behavior, and the diffusion of new products and ideas. By introducing new products, services and ideas into the global marketplace, firms gradually alter traditional patterns of behavior. Thus, the very behaviors that consumer researchers seek to isolate, and study are continually permeated by new and diverse influences (Douglas and Craig 1997).

Here, a central issue is how to develop a clear operational definition of the unit of analysis which is free from the potential confounds arising from the multi-faceted and complex nature of macro-cultural influences and the cultural context in which the unit is studied.

A culti-unit is thus defined in terms of the ethnic, demographic or socio-economic characteristics or specific interests (e.g., ecologically concerned consumers) of its members 
which provide a common bond, and establish a common ethnie, a core of shared "memories, myths, values and symbols woven together and sustained in popular consciousness" (Featherstone 1990). The culti-unit is not a transitory or ephemeral contact group. This ethnie core can typically most appropriately be uncovered through qualitative research. In depth qualitative research is an important first step to gain insights into culture-specific constructs and influences, to identify and to determine what language and terminology should most appropriately be used in studying these constructs. Above all, it can provide important insights into the workings of key forces underlying the changing dynamics of consumer behavior. The challenge for all consumer researchers, not only those directly engaged in cross-cultural research, is to account for the evolving globalization of cultures in the design of research. If they do so at all, consumers tend to attribute different personalities to one and the same brand. A host of knowledge from cross-cultural psychology is now available that helps understand the differences between the concepts of self and personality across countries that lie at the basis of many consumer behavior differences de Mooij and Hofstede (2011). Some products or brands appeal to specific values or motives that are not equally important in all countries. Luxury goods, for example, appeal to the status motive. In some countries, on average, more individuals are driven by the status motive than in others, either a need for social status or more ego-related self-enhancement (de Mooji 2016).

Asian consumers are higher in concern for face and belief in fate, these chronic tendencies only exert a strong influence when they are pertinent to a consumption situation. (Chan et al. 2009). Therefore, globalization has made uneven inroads on consumer attitudes and behaviors, lending credence to conclusion that globalization and cultural homogenization are neither interchangeable nor inevitable (Cleveland et al. 2009).

Exhibit 1. Conceptual model of cultural influence on Foreign New Product Purchase

The companies that are going global should also evaluate the degree of image intensiveness of the environments they are going to operate within (Mikhailitchenko et al.2009). This is needed for assessing the "imagery advertising leverage" those global businesses will have in any particular culture. For example, the Chinese perception of images cannot be considered as overlapping the Italian one. 
Noticeably, cross-cultural studies build upon various sociological and psychological theories. However, our analysis reveals the surprisingly low usage of economic and marketing-related theories. Symbolic consumption has been one of the major motivations among consumers, especially in the last two decades (Aliyev et al. 2017). For example, consumption of luxury items has been increasing steadily, and especially after 2000 the number of studies focused on luxury marketing have increased. However, among cross-cultural studies the interest in symbolic consumption has not been similar (Timokhina et al.2018).

Several pronounced differences exist between Eastern and Western cultures that could be manifested in terms of functional non equivalencies. Differences among Western cultures are not as pronounced, and it may therefore be more difficult to discern the existence of functional nonequivalence. In addition, marketers are becoming more aware of the necessity of selling their products and services to Consumers in the Far East, since that area represents the fastest growing market in the world (Green and Alden 1988).

Managers need to recognize that to be successful, their organization must resist the counteracting pull of home market bias and become "equidistant" (Ohmae 1990) to all the major markets. In order to succeed in international markets, firms need to evaluate home country characteristics and selectively internalize factors which would serve as a basis of sustainable advantage in international markets (Elango and Prakash Sethi 2007).

Moreover, national culture does influence the innovation adoption rates. From a methodological perspective, our findings imply that multi-country research on adoption of innovation could benefit from the inclusion of cultural factors in the research model in addition to the traditional meso and micro factors. An essential message is that even within Europe, large cultural differences exist that substantially affect the adoption of innovations. For instance, in high-context cultures, messages about innovations may be managed effectively through transformational communications by testimonials, good practice examples and industry group meetings, while in low-context countries informational communications via brochures, the Internet, and company visits could be the best way of getting the message of the innovation across (Van Everdingen and Waarts 2003).

Should be considered also the existence of a paradox in the consumer behavior, where the country of origin can represent a strong motivation in adopting a product coming from another culture, dominated by different cultural values. Marketing manager are asked to solve 
that paradox by mean of marketing solution, in communication and in the positioning of the product. In international markets can be found several examples of products coming from a specific culture, being successful in another one for totally different reasons, perceived values and product positioning (Pontiggia and Vescovi 2016).

The following case study, Amarena Fabbri, is an example of cross-cultural approach to the marketing strategies that the company should apply in a totally different market from a cultural point of view, realizing that food is one of the most culturally rooted product categories.

Amarena Fabbri, is an iconic product in Italy by Fabbri 1905 company, due to the long story, and to the success it gained in the years. It is a cherry fruit and syrup sweet product, packed in a ceramic jar, used as topping on ice cream, cakes, pancakes etc. It had a remarkable success in Europe, Argentina and USA and it is exported in 74 countries.

In the confectionery market in China, Fabbri owes a huge experience with business

professionals, concerning syrups and ice cream ingredients. Fabbri aimed to discover Amarena's potential in a B2C context, analyzing the consumer's perception of a traditional Italian product and discovering new potential consumers, as well as new uses. The choice of this item in particular stems from two main reasons: the first, the desire is to analyze how it could be perceived by the Chinese consumers, before the launch on the Chinese market. The second reason is its potential matching with some popular and broadly used confectionary goods that are already present in the Chinese consumer's daily life, like ice-cream, yogurt, and pancakes.

\section{Research method and procedures}

A research has been conducted in order to verify the existence of cross-cultural issues in launching a new product in international market, that has been developed in a different cultural context compare to the one existing of the destination market. The research questions are the following:

RQ1: How much the different cultures existing in the home and the destination markets can affect the perception of the product?

RQ2: The cultural context can force the company to modify the international marketing strategy? 
Following the research questions, we can formulate some research hypotheses.

RH1: The cultural context can heavily influence the product perception by the consumer in a different way, compared to the perception existing in home market.

RH2: in a different cultural context the international marketing strategy of the company should be verified and modified to be adapted to the cultural situation.

Focus group methodology has been chosen as the main tool to analyze consumer perception and purchasing behavior in the confectionery market in China. It allowed us to have direct interaction with Chinese consumers, assured consistency to the research through in-depth qualitative data, open discussions, and models which will help the company to better understand the launch of Amarena product into the consumers market. Three focus groups have been conducted in Shanghai between April and May 2019. Each focus group lasted 2.5 hours. In order to ensure continuity to the research, and to have a quiet and private environment, focus groups took place at Fabbri Headquarter in Shanghai. The team which conducted the meetings was composed by one moderator, one supervisor, and Fabbri Shanghai Marketing manager. Each focus group had a maximum of seven participants similar in age, occupation, income, and education level. The three groups are the following, according con the criteria suggested by Rogers (1983) for new products adoption:

- Group 1 innovators; generation $\mathrm{Z}$ persons;

- Group 2 early adopters; young professionals;

- Group 3 early majority; young mothers.

The sample included young mothers as the primary target. The second focus group has been conducted with a target focus on generation $Z$, young people similar in age (20 - 26) who have a high educational background and are approaching to the working life with their first job. Target income is provided by middle range job salary, and by parents who still help them through economic support. The third target people are comprised of settled down men and women that have already achieved their objective in life, in terms of working position, family and social status. They dispose of a medium high income and are high quality oriented. The participants involved into the focus group had to be conform to some inclusion criteria, like being urban citizens (living in Shanghai); have scarce direct exposure to Western lifestyles. The participants were in prevalence women, but with at least one or two men to obtain more balanced results. For selection, it has been used work and social network community through 
a snowball method (chain-referral sampling method) to reach the desired number of participants. Every target has been engaged in an open discussion. In particular, the dimensions involved in this research were: packaging, taste, suggested use and target. Participants also completed a questionnaire, including 18 questions, through which they were required to explain their personal opinion about the product. In particular, for each dimension they were first asked to complete the questionnaire and then to openly discuss their view. This was because, due to the collectivistic nature of Chinese culture and the bias that this might provoke in a group discussion (e.g. encouraging consensus decision making among group members rather than allowing for a diverse range of opinions to be voiced), obtaining a short personal comment helped to ensure that both participants' individual and collective views have been taken into consideration throughout the focus group discussion.

Schwartz's theory of human value has been chosen as reference, since it is regarded as a cross-culturally validated classification system of personal values experimented in more than 60 countries, including China (Schwartz, 1992). In order to assure the accuracy to this research, each session has been filmed. Each focus group lasted approximately one hour and a half.

\section{Main Findings}

\subsection{Packaging}

For Generation $Z$ participant, Amarena jar has a strong traditional valence, it reminds of a traditional and classic product, and they consider its aesthetic beautiful and attractive. Participants think that due to the uniqueness of Amarena jar, if positioned together with other fruits jam products on the same shelf, it would definitely be the first one to attract their attention. It confirms that the packaging could be a factor able to assure strong competitiveness to Amarena. All the participants agree on the fact that the jar respects the Chinese culture. More specifically, they stress that the flower motif, the shape and the colors have a clear connection to traditional Chinese blue and white vases. However, the participants had a confused perception of the product; in fact, due to the complete covering of the jar, it's nearly impossible to understand correctly the content.

This particular aspect should be taken in greater consideration when entering the Chinese market, as Chinese consumers are always more concerned about the quality and features of 
the products they are buying. If the product is not correctly presented, or is hidden into a completely covered packaging, it would be even more difficult to convince consumers in a purchase decision. Moreover, they were guessing it could be a sweet product as yogurt, or even a salty product, like a pickle jar. In China traditional packaging for pickles are very similar to Amarena Fabbri jars; in fact, they have a white and blue color motif, closed by a lid.

The country of origin, at the moment unrevealed on the jar, together with the ice cream image used for demonstration purposes of Amarena raised unclear perceptions. It confirms once again that the packaging could create a distort perception for Chinese consumers about the real product. All the connections the jar raised into participants minds about the products' origin were never directly related to European countries, at least not to Italy. This aspect should be taken into stronger consideration regarding the bias the packaging itself could bring to about its country of origin.

Moreover, the image displayed on the jar is mainly about ice cream. The participants confirm that they wouldn't buy a product whose main use would be in combination with ice cream because they would never have ice cream in their houses.

Exhibit 2. The Amarena Fabbri Jar.

At first sight, young mothers immediately associated to dairy or sweet related products, but they didn't have a clear idea of its country of origin. They confirm that the attractiveness of this product comparing to other imported fruit jams is really high. Mother's attention is immediately focused on the product ingredients, especially if we are dealing with a sweet product. It means that in buying sweets for their children mothers are concerned about the sugar percentage, and most of the times if it's too high they wouldn't accept to buy them. If the product is too sweet or too high in fat, it would be considered unhealthy and automatically unsuccessful for this target. For a Chinese consumer food should have at first a healthy reason to be eat, while in western country at first is considered the taste. This is due to the cultural aspects connected with the traditional medicine. One aspect that assures mothers about product safety is the glass packaging, which is considered safer than plastic or any other materials. They also consider the jar strange and somewhat inappropriate for a jam jar. They 
would prefer to have a clearer sight of the content in order to feel more assured about the product.

The ice cream image used for demonstration purposes of the product causes a huge barrier in a potential purchase decision made by young mothers. In fact, mothers are very restrictive about giving iced and cold products to their children. This aspect stems from the Chinese culture and tradition to prefer warm and hot products on cold ones, considered unhealthy.

The shape and the design of the packaging make the participants think about pickles, that are considered as a no-fresh, too salty, and not-healthy food product.

The product's description translated in Chinese on the lid of the jar results very vague for Professionals. They explain it is caused by the use of a confusing font and an unclear description of the ingredients. The brand repetition all over the jar results to be confusing for the participants. According to Chinese consumers, the brand should stand out from the packaging. That means it should have an outstanding color, different from the others used for the packaging itself, and it should have a proper space, in order to be clear and noticeable. Participants criticized the Chinese translation for Guojiang “jam”, because the product's content is entire pieces of cherry fruit and cherry syrup, that means "jam" translation is not

appropriate. Even if, participants consider the expression fruit and fruit syrup on a jar strange for the Chinese market and difficult to understand. They consider the English version "Fruit and syrup", more precise and accurate.

\subsection{Taste dimension}

According to Generation Z participants, the taste experience of Amarena was overall positive, even if the product sweetness for the majority of them was too intense. Overall, their perception about Amarena is that the product should be matched with other flavors to reduce the sweetness and the intensity of the cherry, unlikely to be eaten by itself.

They spontaneously perceived yogurt as a perfect match for Amarena, because it is a wellknown product for Chinese consumers in general, and because they are used to prepare it at home. However, they still consider ice cream as a not directly appropriate food product for Chinese consumers. This is designated to be only an Italian typical and traditional use. 
According to young mothers, the flavor by itself reminds them of Chinese medicine cough syrup. They would directly consider the product as unhealthy because the sweetness is too strong and difficult to be accepted.

\subsection{Suggested use}

Generation $Z$ participants said that although Amarena Fabbri mainly reminds them of Chinese cough syrup, they stated they would be curious to use Amarena in some of Chinese traditional recipes, as for example pork braised meat or any other dishes of Shanghai, Chengdu, Guangzhou cuisine that are typically recognized for their sweet and sour mixed flavors. Due to its perfect combination with yogurt, participants would also consider milk or milk custard as a possible match. They related Amarena also to Italian wine or cocktails, pancakes, smoothies, bitter flavor ice cream (to create contrast with the cherries' sweetness), bitter fruits, spirits and sparkling water, or it could be used as a decoration on cakes and bakery products.

Generation Z participants perception before and after Amarena tasting in combination with other products changed a lot. They defined Amarena as a versatile product and it generally tastes better when used in combination with other sour product rather than alone. However, they perceive it to be a product for a niche market, whose consumers are updated about latest food industry imported products.

They explained that, to reduce the sweetness, they would prefer to associate Amarena to something colder or at least fresher. In fact, they enjoyed Amarena most in combination with smoothie and ice cream; they raised an easy recipe that is becoming even more popular among Generation Z participants, called bingfen, literally it is a salad prepared with ice cubes and flavorings like sauces, milk, or syrups. They explained that in relation to the Chinese cuisine they would probably only use it in combination with fermented glutinous rice or yogurt.

The Chinese cuisine doesn't include any dessert, so the population is not accustomed to enjoying this flavor.

Professionals participants, in particular, stated different recipes of the Chinese cuisine which could embrace the cherries flavor. They include traditional savory and sweet recipes, like: dousha tangyuan, a special type of Chinese dumplings made of glutinous rice flour served in 
soup and filled with sweetened red bean paste, and dousha zongzi, a pyramid-shaped dumpling made of glutinous rice wrapped in bamboo or red leaves, filled with sweetened red bean paste; participants think that they both could be filled with Amarena cherry and syrup. Sweet and sour mandarin fish (deep-fried mandarin fish in sweet and sour sauce), double cooked pork slices, spareribs braised in brown sauce, according to participants, could involve Amarena as part of their ingredients and becoming part of new creative combinations.

\section{Discussion}

Collecting this kind of information will help us understanding under which values or influences consumers could feel more engaged in the purchase of this kind of product.

A hypothetical purchase decision could be raised from the packaging itself. Some of our participants think that the product could be more suitable for a present, rather than being a personal purchase. They all agree about the fact that Amarena could be a proper gift to bring at their dinner parties. The reason is twofold, the packaging itself is beautiful, but more in depth, this gift leaves to its owner the final decision to open it immediately or not. This could be an intrinsic sign of politeness for the Chinese culture, giving expression of respect and gratitude for the invitation.

Exhibit 3. different perceptions in home and destination markets

Nevertheless, generally speaking, Chinese consumers feel more assured about an imported product quality, rather than Chinese food processed products. Young mothers would consider buying a new product online only if they perceive a specific need, and they would mainly rely on votes and feedbacks of other consumers, which must be above $50 \%$ of agreements. When a new product shows a high selling rate, even if the knowledge and experience about it might be low, they could be curious about trying it. In their purchasing decision, friends' opinions are considered more important than online feedbacks, and advises from colleagues or other mothers even more important than friends' opinions. In general, all three groups consider word of mouth as the fundamental tool to share information.

In introducing a new product in a different culture many cross-cultural issues emerge. The case of Amarena Fabbri is an evident example of it. The country of origin, Italy, and the 
country of destination, China, are embedded in really different cultures even if we are acting in a global economy. To this evidence should be added the characteristics of a non-acquainted market. In other words, two are the main factors that should be considered in entering a culturally distant market: a) the low level of knowledge of the product; b) the different product environment (use, perception, role, complementarity etc.).

Paradoxically, what is considered a strength in the home country and in traditional western markets culturally similar to the home market (sweetness, packaging, brand, shelf life, country of origin, etc.), turn in weakness in a far culture destination country as China (see exhibit 3), caused by different cultural references and no knowledge about the product, being it new for the market. Some consumers habit as how they use some products (i.e. no one eat ice cream at home in China, while it is extremely common in Italy), as well as context elements (different traditional cuisine recipes), make the use of the product difficult or at least really different, unexpected by the company, ready to replicate the marketing strategy that was successful in its traditional foreign markets. Marketing strategies, as communication, packaging, branding, pricing and distribution should totally be rethought and adapted to the different cultural context. The company had to reconsider any marketing strategy that was design for the product lunch in the Chinese market, changing the communication, the suggested use, modifying the packaging and the product name.

\section{Conclusions, practical implication and limitation}

Despite the globalization of the economy is affecting the consumer behavior by mean of the worldwide diffusion of global products and global purchase habits, different cultures are influencing deeply the development, perception, usage and appreciation of the products. We can consider that, due to the opening of new important markets embedded in a different culture, as China, and Asian south East (Vietnam, Cambodia etc.) or future markets as African ones, the cross-cultural aspects will be more and more important in every international marketing strategy. It means that the international marketing activities should be redesigned in order to fit expectations and costumes not considered by the company during the product development in the home market, where a different context culture suggested consistent solutions with that particular culture. 
Both hypotheses 1 and 2 are therefore confirmed. The finding demonstrated that the cultural context can heavily influence the product perception by the consumer in a different way in a far culture market, and the international marketing strategy of the company should be modified to be adapted to the local cultural situation.

Marketing manager should avoid the easy and shortcut to replicate the strategies and action that have been successful in other markets. It would be a really risky and ruinous business behavior. They should study the cultural context seriously and adapt the marketing strategies as well some product features to the destination market. The markets are becoming more and more acquainted about brands and products, giving the false perception of homogeneity. In reality, while there is an evident convergence on the surface of the international markets, there is a cross-cultural issue under that surface, different in deepness depending on different product categories, but strongly influencing the consumer behavior in new and unexpected forms. Cultural differences are sometime subtle and difficult to be perceived, analyzed and understood. For this reason, they are often really important and strategic. As the case of Amarena Fabbri demonstrate, sometimes the swot analysis should be remade in total and the marketing strategy of the company totally rethought.

This paper used only one case study and the sample that has been used was selected in the most international city of China. We used just one investigation method, the focus group, that should be integrated with other consumer analyses, both qualitative and quantitative. An interesting further step would be to increase the number of cases and to include different cultural area of that big country as China is. Moreover, a reverse research, for example, China to Italy or China to Europe, should be done in order to validate the initial finding. These are the main limitations of this research that is only the starting point for a more robust analysis, enlarged to a broader number of countries. The cross-cultural marketing research should be renewed in the present global economy.

\section{References}

Chan H., Wan L.C., Sin L.Y.M. (2009), "The Contrasting Effects of Culture on Consumer Tolerance: Interpersonal Face and Impersonal Fate", Journal of Consumer Research, Vol. 36, Issue 2.

Clark, T. (1990), "International marketing and national character: a review and proposal for an integrative theory", Journal of Marketing, Vol. 54, pp. 66-79 
Cleveland M., Laroche M., Papadopoulos N, (2009) "Cosmopolitanism, Consumer Ethnocentrism, and Materialism: An Eight-Country Study of Antecedents and Outcomes" Journal of International Marketing, Vol. 17, No. 1.

de Mooij M., (2011) Consumer behavior and culture: consequences for global marketing and advertising, Sage.

de Mooij M., Hofstede G. (2011) "Cross-Cultural Consumer Behavior: A Review of Research Findings", Journal of International Consumer Marketing, vol. 23, n 3-4:181-192,

de Mooij M. (2013), "On the misuse and misinterpretation of dimensions of national culture", International Marketing Review, Vol. 30 No. 3.

de Mooij M. (2016) "Comparing dimensions of national culture for secondary analysis of consumer behavior data of different countries", International Marketing Research, vol 34, n. 3, p. 446.

Delener, N. and Neelankavil, J.P. (1990), "Informational sources and media usage: a comparison between Asian and Hispanic subcultures", Journal of Advertising Research, Vol. 30 No. 3, pp. 45 52.

Douglas S.P., Craig C.S. (1997) 2The changing dynamic of consumer behavior: implications for cross-cultural research", International Journal of Research in Marketing, 14, 379-395

Elango B. and Prakash Sethi S. (2007), "An Exploration of the Relationship between Country of Origin (COE) and the Internationalization-Performance Paradigm", Management International Review, vol. 47, n. 3.

Engel, J.F., Blackwell, R.D. and Miniard, P.W. (1993), Consumer Behaviour, The Dryden Press, Fort Worth, TX.

Featherstone, M. (Ed.), 1990. Global Culture: Nationalism, Globalism and Modernism. Sage, London, pp. 1-14.

Fu J.H.Y. \& Chiu C.Y., (2007) "Local culture's responses to globalization: Exemplary persons and their attendant values", Journal of Cross-Cultural Psychology, vol 38 n. 5.

Giddens A., (2000) Runaway world, New York: Routledge.

Green R.T. and Alden D.L. (1988), "Functional Equivalence in Cross-Cultural Consumer Behavior: Gift Giving in Japan and the United States”, Psychology \& Marketing, Vol. 5(2), Summer.

Hall T. E. (1976), Beyond culture, Anchor Books.

Hall T. E. (1984), The dance of life, Anchor Books.

Hall T. E. (1988), The Hidden Dimension, Anchor Books.

Hirschman, E.C. (1981), "American Jewish ethnicity: its relationship to some selected aspects of consumer behaviour", Journal of Marketing, Vol. 45, pp. 102-10.

Hofstede G. (1991) Organizations and cultures: Software of the mind, McGrawHill, New York.

Hofstede G., (2010), Cultures and organizations: Software of the mind, McGraw-Hill.

Hofstede G. (2003,) Culture's Consequences, Sage.

House R. J. \& associates (2004), Culture, leadership, and organizations: The GLOBE study of 62 societies,. CA: Sage

Inglehart R., Basanez M., Moreno A. (1998) Human values and beliefs, The University of Michigan Press.

Levitt T. (1983), "The Globalization of Markets", Harvard Business Review, May-June, pp. 92-102.

Luna D. and Gupta S.F. (2001), "An integrative framework for cross-cultural consumer behavior", International Marketing Review, Vol. 18 No. 1. 
McCracken, G. (1986), "Culture and consumption: a theoretical account of the structure and movement of the cultural meaning of consumer goods", Journal of Consumer Research, Vol. 13, pp. 71-84.

Mikhailitchenko A., Rajshekhar G., Mikhailitchenko G., (2009) "Laroche M. Cross-cultural advertising communication: Visual imagery, brand familiarity, and brand recall", Journal of Business Research, vol. 62.

Minkov M., (2007), What makes us different and similar: A new interpretation of the World Value Survey and other cross-cultural data, Klasika i Stil Publishing House.

Mooney P. (2002), "Learning the old ways" Newsweek.

Nakata, C. and Sivakumar, K. (1996), "National culture and new product development: an integrative review", Journal of Marketing, Vol. 60, pp. 61-72.

O'Guinn, T.C. and Meyer, T.P. (1984), "Segmenting the Hispanic market: the use of Spanish language radio", Journal of Advertising Research, Vol. 23, pp. 9-16.

Oyserman, D. (2015), "Values, psychological perspectives", in Wright, J.D. (Ed.), International Encyclopedia of the Social \& Behavioral Sciences, 2nd ed., Vol. 25, Elsevier, Oxford, pp. 36-40.

Pontiggia A. and Vescovi T, (2016), Panni stesi a Pechino. Esploratori e pionieri nei nuovi mercati internazionali, Egea.

Rogers, E.M. (1983), Diffusion of Innovations, 3rd ed., The Free Press, New York, NY.

Rohner R.P. (1984), “Toward a Conception of Culture for Cross-Cultural Psychology”, Journal of Cross-Cultural Psychology, vol.15, n. 2.

Robertson R. (1992), Globalization, Sage.

Singh S. (2006), "Cultural differences in, and influences on, consumers' propensity to adopt innovations", International Marketing Review Vol. 23 No. 2, pp. 173-191

Suerdem A. (1994), "Social de(re)construction of mass culture: Making (non)sense of consumer behavior", International Journal of Research in Marketing, Volume 11, Issue 4, September, Pages 423-443

Schwartz, S.H. (1992), "Universals in the content and structure of values: theoretical advances and empirical tests in 20 countries", Advances in Experimental Social Psychology, Vol. 25, pp. 1-65.

Schwartz, S.H. (1994), "Beyond individualism/collectivism”, in Kim, U., Triandis, H.C., Kâğitçibaşi, Ç., Choi, S.-C. and Yoon, G. (Eds), Individualism and Collectivism: Theory, Method, and Applications, Vol. 18, Cross-cultural Research and Methodology, Sage, Thousand Oaks, CA, pp. 85-119.

Schwartz, S.H. (2006), "Studying values: personal adventure, future directions", Journal of CrossCultural Psychology, Vol. 42 No. 2, pp. 307-319.

Smith P. (2006), "When elephants fight, the grass gets trampled: The GLOBE and Hofstede projects", Journal of international Business Studies, vol. 37.

Soares A.M., Farhangmehr M., Shoham A. (2007) "Hofstede's dimensions of culture in international marketing studies", Journal of Business Research, Volume 60, Issue 3, March.

Terlutter, R., Diehl, S. and Mueller, B. (2006), "The GLOBE study - applicability of a new typology of cultural dimensions for cross-cultural marketing and advertising research", in Diehl, S. and Terlutter, R.R. (Eds), International Advertising and Communication. Current Insights and Empirical Findings, Gabler Edition Wissenschaft, Wiesbaden, pp. 421-438. 
Timokhina G., Taylan U., Wagner R. (2018), "Cross-Cultural Variations in Consumer Behavior: a Literature Review of International Studies", South East European Journal of Economics and Business, Volume 13 (2).

Trompenaars, F. (1993), Riding the Waves of Culture. Understanding Cultural Diversity in Business. Nicholas Brealey, London.

Van Everdingen Y.M.and Waarts E. (2003), "The Effect of National Culture on the Adoption of Innovations", Marketing Letters, vol. 14:3.

Exhibit 1. Conceptual model of cultural influence on Foreign New Product Purchase

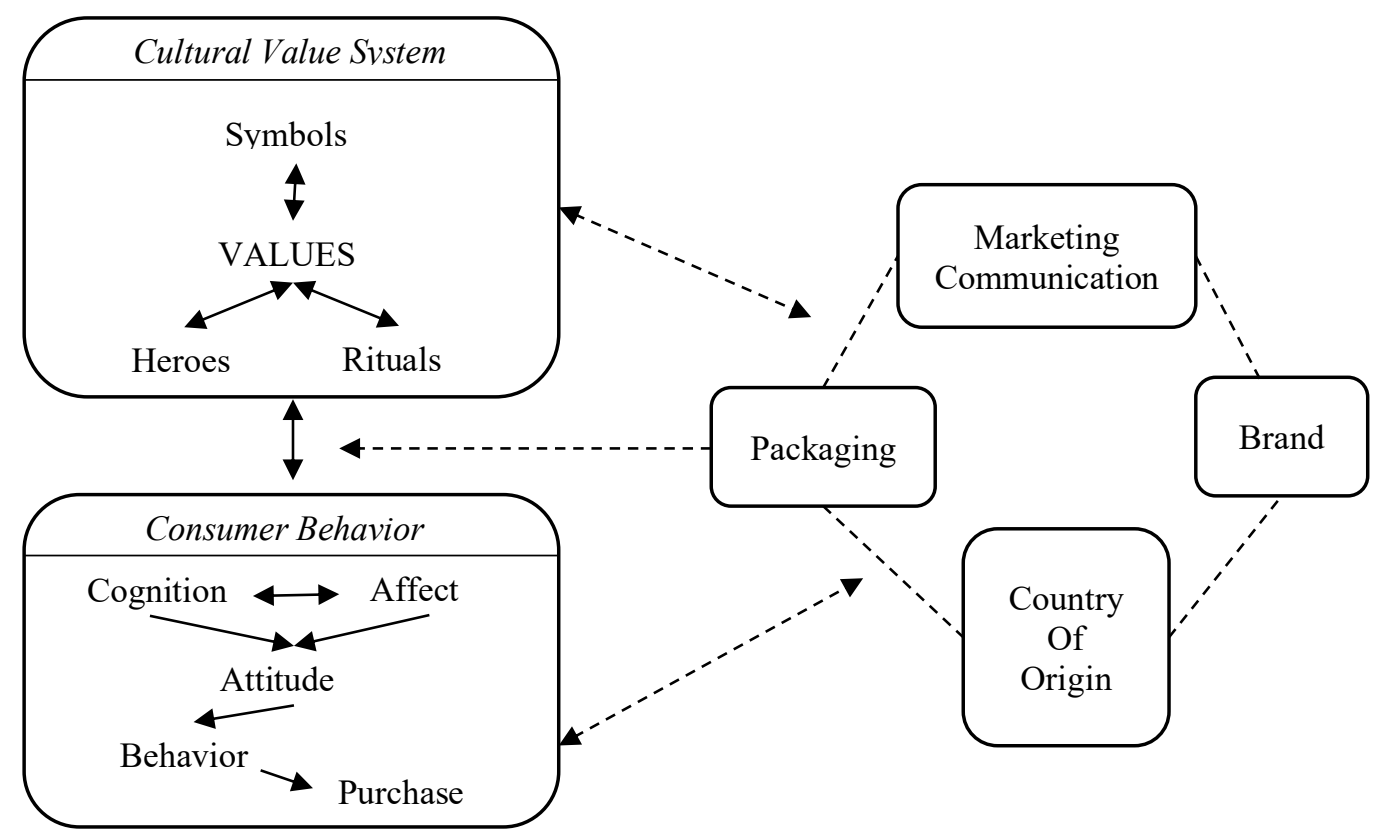

Adaptation from Luna D. and Forquer Gupta S. (2001).

Exhibit 2. The Amarena Fabbri Jar.

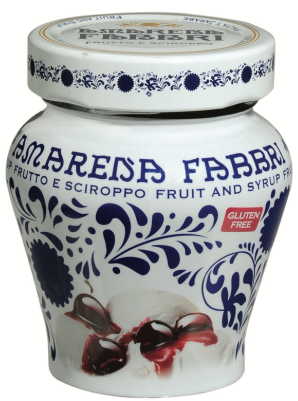


Exhibit 3. different perceptions in home and destination markets

\begin{tabular}{|c|c|c|}
\hline $\begin{array}{l}\text { Characterisites of } \\
\text { the offer }\end{array}$ & Home Market (Italy) & Destination Market (China) \\
\hline $\begin{array}{l}\text { Country of origin } \\
\text { effect }\end{array}$ & $\begin{array}{l}\text { Very positive and valuable, generally } \\
\text { considered a point of strength }\end{array}$ & Confused, perceived as "western" \\
\hline Package & $\begin{array}{l}\text { Very distinctive, identity, } 4 \text { sizes, } \\
\text { clear information }\end{array}$ & $\begin{array}{l}\text { Confusing, unclear, hiding the } \\
\text { product, smaller sizes }\end{array}$ \\
\hline Food expectations & 1 taste, 2 organic, 3 healthy & 1 healthy, 2 organic, 3 taste \\
\hline Product definition & Clear & Confusing \\
\hline Brand & $\begin{array}{l}\text { Well known, traditional, high } \\
\text { reputation }\end{array}$ & Unknown, not evident, no reputation \\
\hline $\begin{array}{l}\text { Perception of } \\
\text { sweetness }\end{array}$ & $\begin{array}{l}\text { Perfectly fitting with the expectations, } \\
\text { consistent with the use, appreciated }\end{array}$ & Too intense, need to be reduced \\
\hline Suggested use & Ice cream, cakes, dessert & $\begin{array}{l}\text { Sweet and sour dishes (pork, fish, } \\
\text { rice), bitter food (yogurt) }\end{array}$ \\
\hline Price & In line with jam & Premium, expected discount \\
\hline Gift role & None, personal consumption & Perfect for a gift to a woman or kids \\
\hline Shelf life & Correct & Suspicious \\
\hline
\end{tabular}

